\title{
Literacy level of mothers and its association with nutritional status of children under five years of age, in rural area of Lahore
}

\author{
Farah Batool $^{1^{*}}$, Meshal Margrate ${ }^{2}$, Munazza Tasneem ${ }^{3}$ and Ambreen \\ $\mathrm{Nasir}^{4}$ \\ 1. Nursing Campus, Superior University, Lahore-Pakistan \\ 2. Akhtar Saeed College of Nursing, Lahore-Pakistan \\ 3. Children Hospital \& ICH, Lahore-Pakistan \\ 4. Punjab Ranger's teaching Hospital, Rahbar medical \& Dental College, Lahore-Pakistan \\ *Corresponding author's email: farahbatool2014@gmail.com
}

Citation

Farah Batool, Meshal Margrate, Munazza Tasneem and Ambreen Nasir. Literacy level of mothers and its association with nutritional status of children under five years of age, in rural area of Lahore. Pure and Applied Biology. Vol. 9, Issue 2, pp1619-1626. http://dx.doi.org/10.19045/bspab.2020.90170

\begin{tabular}{llll}
\hline \hline Received: 01/12/2019 & Revised: 22/02/2020 & Accepted: 09/03/2020 & Online First: 24/03/2020 \\
\hline \hline
\end{tabular}

\section{Abstract}

Nutrition has been entitled one of the immensely disregarded opportunities in sustaininoptimal health status especially in growing children of developing countries, like Pakistan There is scarcity of community level studies on malnutrition and educational level of mothers in rural areas. So, the objective of this study was to find out the association of mother's literacy level to child's nutritional status because it will be helpful to understand the widespread problem. Furthermore, future planning may be based on improving maternal education, to overcome the issue of under nutrition. A community based Cross sectional descriptive study carried out in a rural area of Mustafa abad (Liliani), Lahore; Pakistan. Data was collected from April to August, 2018. Convenient sampling technique was used. Nutritional status of children was measured by using the anthropometric measurements and sorting them out as wasting, stunting and under-weight, according to criteria of World Health Organization, for under nutrition. Data was analyzed by entering in SPSS version-20. Results illustrate a significant association among mothers' literacy level to child nutritional status (p-value 0.020). Majority of the mothers with high school and above educational level have had high proportion of children with standard nutrition status while the children whose mothers had stumpy level of education were presented with stunting. Malnutrition is widespread in our country at distressing point. This is a dire need to improve the educational level of mothers since it has been a significant association with the nutritional state of our children. Keywords: Anthropometry; Malnutrition; Stunting; Underweight; Wasting

\section{Introduction}

Despite extensive progress towards eradicating extreme poverty and hunger in developing countries, nutrition has been still entitled one of the immensely overlooked opportunities [1]. Malnutrition is the cellular imbalance between the supply of essential nutrients, calories and ability of the body to 
utilize it, for the growth and maintenance of particular functions, malnutrition may be under nutrition or over nutrition [2]. Indicators of under nutrition are, abnormalities in growth, in term of stunting, wasting and underweight [3].

Under nutrition is a major public health concern, among children $<5$ years of age in developing countries and is even increasing with time [4]. Globally, 20 million children of this age group, suffered from malnutrition, death of almost one million children per year in developing countries, is due to malnutrition [5]. According to UNICEF, 90\% undernourished children of developing world are found in South Asia and Africa; whereas $40 \%$ of the world's malnourished children are the residents of India and Pakistan [6]. In Pakistan, four out of 1 ten under five (40\%) children are stunted according to the new National Nutrition Survey (NNS, 2018); while $17.7 \%$ are suffered from wasting. The double burden of under nutrition is becoming increasingly apparent, with almost one in three children underweight (28.9\%), which clearly shows the poor nutritional status of children in Pakistan.

Nutrition plays a crucial role in growth and development of children, deficient nutrition may leads to retarded growth, poor learning skills, reduced competence to perform different tasks, inability to resist diseases, exhibited poor cognition, psychological/ behavioral disorders and problems in social development [7]. Moreover, it also causes to reduce the academic achievement of children, short stature and increased risk of getting diseases during childhood as well as in adulthood which further leads to increase the economical burden of developing country by increasing the incidence of diabetes, hypertension, and dependency along with psychological problems [8].

Factors affecting malnutrition have been recognized in different studies in diverse settings, including improper weaning, low birth spacing, number of children, incomplete immunization, repeated bout of illness, poverty, literacy level of mother and mother's nutrition related knowledge [9]. Studies confessed that mothers are the chief care providers of children, their understanding of elementary nutrition and health related dealings sturdily influence the care which they provide to their children [10]. During last twenty years, a significant amount of information are obtainable from under developed countries which demonstrated that maternal literacy has a strong collision on nutritional status along with child's mortality [1]. Additionally, Female's literacy rates are not only seen to be associated significantly in reduction of the percentage of children being stunted, underweight or wasted, but also contributes in bringing down the child mortality rate [11].

As educated mothers are better able to seek timely medical treatment for their children, cognitive skills helps them in early detection of childhood nutritional and wellbeing problems, increased familiarity with modern society enable mother to become more receptive for latest treatment and interventions for diseases [12]. On average each year, there is a 7-9\% turn down in child's mortality corresponds to rise in maternal literacy level [13].

Poverty has a strong linkage with under nutrition, studies documented a well-built relationship between maternal education and socio economical status because knowledgeable women are more proficient to get sound, sound paying employment; elevated income as well, so they may demonstrate better insightful of growing children [14]. On the contrary, Mothers with low educational level generally display worse health outcome of their children [15].

Mothers' educational status appears a fundamental skill for well-nourished children even with low socio economical status [11]. 
However, studies has manifested that greater tendency for educated mothers/ care takers to do work away from their home exhibits a additional mechanism that the employment of mother has an adverse effect in some nations, but most of the researches have unsuccessful to discover such a consequence, perhaps because of the counteracting influence to the contribution of mother's income to household earnings [16]. The intention of this study is to better understand the association of mother's literacy level to nutritional status of children in a rural community of Lahore, Pakistan.

\section{Materials and methods}

A cross sectional descriptive study was carried out at Mustafa Abad (Liliani), District Kasur, Lahore; Pakistan. Convenient sampling technique was applied and the target population was mothers having children 6-59 months of age in selected study area; calculated sample size was 100 mothers and 100 children. A self-structured questionnaire was used for data collection, having demographical data including educational level of mothers and the height/length along with weight of children. The questionnaire was pilot tested and reliability of the tool was computed by using Cronbach's alpha for pilot study. The study tool had two parts: Part 1: The socio economical data sheet which elicited responses to describe the participants' socio economical overview and educational level of mothers. Part 2: Anthropometric measurements were used to determine the health status of children by using under nutritional indicators namely; stunting, wasting and underweight, according to $\mathrm{WHO}$ criteria.

Measuring tape and weighing scale was used for anthropometric data collection. To evaluate the child's nutritional status, weight and length (height) was taken. The scale was calibrated at the beginning of each day, as well as during the day at regular intervals.
Children were weighed with slightest clothing, and the weight was taken to the nearest $0.1 \mathrm{~kg}$. Recumbent lengths of the children were noted, so each child was made to lie on a wooden board and length measurements were calculated to nearby of $0.1 \mathrm{~cm}$.

Data was entered and evaluated by using SPSS Version 20, along with MS Excel. Weight and height/length were used to categorize the children to underweight (weight-for-age), wasted (weight-for-height) and stunted (height-for-age) by means of the WHO Anthro ( $v$ for personal computers 3.2.2) [17]. The indices were expressed by using the international reference population as $\mathrm{Z}$ scores. Children were grouped as, wasted underweight and stunted, if the $\mathrm{z}$ scores fell below -2SD of the reference population respectively for the age and sex. Descriptive statistics (means, standard deviations, percentages and range) was computed for socio demographic data. A Pvalue of less than 0.05 was considered significant in entire analyses. A chi-square and Fisher Exact test was used for association of child's nutritional status to literacy level of mother.

\section{Results}

\section{Socio-Demographic data}

This section presented socio demographic data particularly about age of the participants under study both mothers and their children. The proportion of female study children were higher as compared to male gendre. More than half of the participants $(53 \%)$ were female whereas, $47 \%$ were male.

Most of the participants (55\%) were sorted out in to the age group of 01 to 03 years, whereas $33 \%$ were from 3 to 5 years of age. However, $32 \%$ children were having age above than three years.

About half of the families (45\%) had monthly income less than RS.10, 000, Hence, 32\% family units had monthly income RS.> 
10,000 and rest of the study family units had monthly earning of only RS.10, 000 .

Approximately half of the mothers were illiterate $(45 \%)$, they were unable to read or write anything. While $38 \%$ of the mothers were educated up to primary or metric (5 to 10 years of schooling) level, only $17 \%$ mothers had acquired college/university level education (14 to 16 years).

\section{Nutritional status}

$48 \%$ children were exhibited normal growth, rest of the children presented with some kind of under nutrition. $28 \%$ children had stunting, $17 \%$ were found underweight and $7 \%$ children were caught up with wasting. The number of stunting was highest $28(54 \%)$ among children having under nutrition, whereas wasting was lowest $7(13 \%)$ among malnourished children. Underweight was $17(33 \%)$. Rest of the children was having normal nutritional status $48 \%$. There is a noteworthy association among literacy level of mothers and nutritional status of children, as $\mathrm{p}$ value is 0.020 .

\section{Discussion}

Most of the children in present study (55\%) were fall within the age group of 1 to 3 years. Gender wise $53 \%$ of the children were female and $47 \%$ were male (Table $1 \& 2$ ). These findings are in line with Damor et al.[18] who observed nearly equal allocation of children in their study.

When we talk about the prevalence of malnutrition, its coverage was higher amongst female as compared to male children. This elevated proportion of malnutrition observed in female children may be due to the presence of high number of female children in this study. Chakraborty also documented the high fraction of female children flaunt under nutrition [19]. Studies have recognized gender difference with regards to under nutrition in young children predominantly [20].

Under nutrition is an indicator of deprived nutrition and under-privileged health of a population, especially in developing countries [12]. Our study identified more than half of the children (52\%) has some kind of under nutrition i.e. stunting, wasting \& underweight. The findings of current study are congruent with community-based studies carried out in Sri Lanka, Khyber Pakhtunkhwa (Pakistan) \& India respectively $[19,21,22]$. Current study findings demonstrate, highest prevalence of Stunting among malnourished children 28(54\%), underweight $17(33 \%)$ and wasting was 7(13\%), (Figure.1). However, a community based study in Nairobi has reported stunting rate $40 \%$ in under five years children in 2012 [23]. Additionally, National Nutritional Survey (2018) documented, 43\% stunting, $18 \%$ wasting \& underweight $32 \%$, in rural areas of Pakistan.

Stunting is an indicator of chronic malnutrition in which children display compromised physical and mental growth along with past and present under nutrition [24]. Our findings has highlighted peak rate of stunting among malnourished children than underweight or wasting. Most of the stunted children were belonged to illiterate mothers, whereas highest number of children with normal nutritional status was fit in to mothers having high educational level. A study in Cambodia stated that mother's literacy level is inversely associated with stunting [25]. A study presented that mothers with primary level of education (5 years of schooling) exhibited high number of children with stunting as compared to mothers having secondary/ middle level ( 8 to 10 years of schooling) education. Low level of maternal education is a well-built predictor of childhood stunting [22].

The current study proved that economical status of the study population was poor, about half $(45 \%)$ of the families has monthly income less than 10,000 rupees (Table 3), although mothers with increased years of schooling had better nutrition status of their 
children as compared to families where the mothers were illiterate (Table 4). These finding are comparable with the findings of Shafqat et al. [26] that mother's educational level is closely associated with nutritional status of children because educated mothers have rational food selection for their children and encompass more autonomy as compare to uneducated mothers. In addition, educated mothers may contribute to improve the earning of the family; good socio economical status of the family is also one of the positive precursors for the normal physical \& mental growth of children.

Table 1. Distribution of children according to sex/gender

\begin{tabular}{|c|c|c|}
\hline Sex/ Gender & Frequency & Percent \\
\hline Male & 47 & 47.0 \\
\hline Female & 53 & 53.0 \\
\hline Total & 100 & 100.0 \\
\hline
\end{tabular}

Table 2. Age of children

\begin{tabular}{|c|c|c|}
\hline Age in months & Frequency & Percent \\
\hline $\mathbf{6 - 1 2}$ & 12 & 12.0 \\
\hline $\mathbf{1 3}-\mathbf{2 4}$ & 29 & 29.0 \\
\hline $\mathbf{2 5}-\mathbf{3 6}$ & 26 & 26.0 \\
\hline $\mathbf{3 7}-\mathbf{4 8}$ & 17 & 17.0 \\
\hline $\mathbf{4 9}-\mathbf{6 0}$ & 16 & 16.0 \\
\hline Total & 100 & 100.0 \\
\hline
\end{tabular}

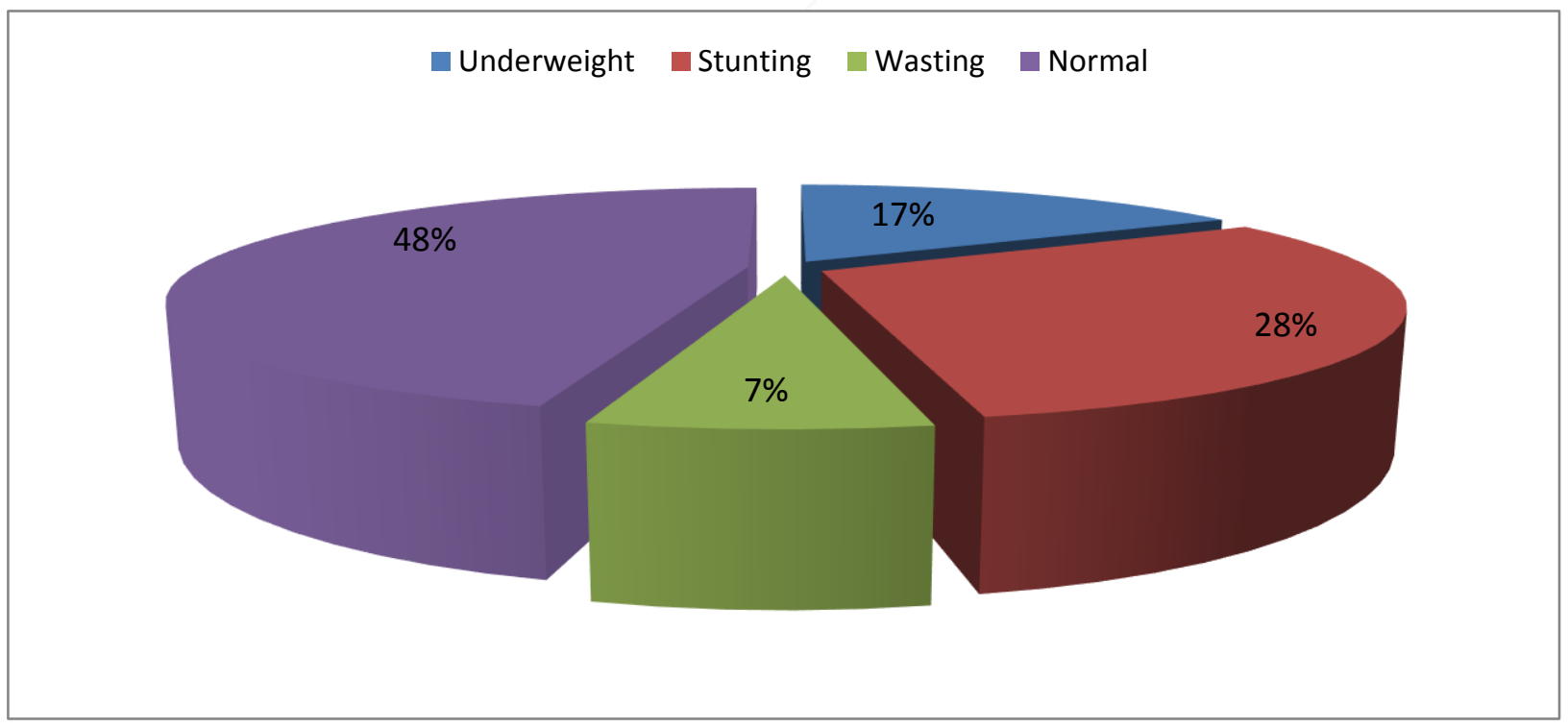

Figure 1. Nutritional status of children

Table 3. Per month income of families

\begin{tabular}{|c|c|c|}
\hline Income per month & Frequency & Percent \\
\hline$<\mathbf{1 0 , 0 0 0}$ & 45 & 45.0 \\
\hline $\mathbf{1 0 , 0 0 0}$ & 23 & 23.0 \\
\hline$>\mathbf{1 0 , 0 0 0}$ & 32 & 32.0 \\
\hline Total & 100 & 100.0 \\
\hline
\end{tabular}


Table 4. Association of Mother's literacy level to nutritional status of children



Fisher's exact test, $\mathrm{p}$-value $=0.020$, Significant association

\section{Conclusion}

Improving schooling years of mothers, may have momentous influence on nutritional conditions of children, socio economical status, disease prevention, and early medical aid seeking behavior. It will eventually change the poverty series, as stunting (height/age) is a key predictor of human resources. It is also suggested that including health related knowledge and skills in school curriculum may result in significant improvement in nutritional status of children by facilitating the future mothers to display a better health related knowledge, practice and obviously behavior as well.

\section{Authors' contributions}

Conceived and designed the experiments: F Batool \& M Margrate, Performed the experiments: F Batool \& M Tasneem, Analyzed the data: A Nasir, Contributed materials/ analysis/ tools: M Margrate, Wrote the paper: F Batool,

\section{Acknowledgement}

I would like to special tribute to my contemporaries for help, I would be gratitude to my parents, husband along with my children, who all helped me in completing the study successfully.

\section{References}

1. Mathers CD \& Loncar D (2006). Projections of global mortality and burden of disease from 2002 to 2030. PLoS Med 3(11), e442.

2. World Health Organization. (2005). The World health report: 2005: make every mother and child count.

3. Kruger G, Pienaar AE, Coetzee D \& Kruger SH (2014). Prevalence of stunting, wasting and underweight in Grade 1-learners: The NW-CHILD Study. Health SA Gesondheid 19(1). 
4. Asad N \& Mushtaq A (2012). Malnutrition in Pakistani children, its causes, consequences and recommendations. The $J$ of the Pak Medical Assoc 62(3): 311.

5. Laghari ZA, Soomro AM, Tunio SA, Lashari K, Baloach FG, Baig NM \& Bano S (2015). Malnutrition among children under five years in district Sanghar, Sindh, Pakistan. Gomal J of Med Sci 13(1).

6. UNICEF, Division of Communication (2009). Tracking progress on child and maternal nutrition: a survival and development priority. Unicef.

7. Manna PK, De D, Bera TK, Chatterjee K \& Ghosh D (2011). Anthropometric assessment of physical growth and nutritional status among school children of North Bengal. The Anthropol 13(4): 299-305.

8. Johri M, Subramanian SV, Koné GK, Dudeja S, Chandra D, Minoyan N \& Pahwa S (2016). Maternal health literacy is associated with early childhood nutritional status in India. The $J$ of Nutr 146(7): 1402-1410.

9. Tette EM, Sifah EK \& Nartey ET (2015). Factors affecting malnutrition in children and the uptake of interventions to prevent the condition. $B M C$ Pediat 15(1): 189.

10. Semba RD, De Pee S, Berger SG, Martini E, Ricks MO \& Bloem MW (2007). Malnutrition and infectious disease morbidity among children missed by the childhood immunization program in Indonesia. Southeast Asian J of Tropical Med and Public Health 38(1): 120.

11. Goel PA \& Malhotra P (2018). Impact of Female Literacy and Workforce Participation on Child Nutritional Status in India: Panel Data Estimation. OIDA Inter J of Sustainable Devel 11(04): 1116.
12. Das $\mathrm{S} \&$ Sahoo H (2011). An investigation into factors affecting child undernutrition in Madhya Pradesh. The Anthropol 13(3): 227-233.

13. Cleland JG \& Van Ginneken JK (1988). Maternal education and child survival in developing countries: the search for pathways of influence. Social Sci \& Med 27(12): 1357-1368.

14. Raju D, Kim KY, Nguyen QT \& Govindaraj R (2017). Cities, slums, and early child growth: empirical evidence from Bangladesh. The World Bank.

15. DeWalt DA \& Hink A (2009). Health literacy and child health outcomes: a systematic review of the literature. Pediat 124(Suppl 3): S265S274.

16. Smith LC, Ruel MT \& Ndiaye A (2005). Why is child malnutrition lower in urban than in rural areas? Evidence from 36 developing countries. World Devel 33(8): 1285-1305.

17. World Health Organization (2009). WHO Anthro for personal computers: software for assessing growth and development of the world's children (version 3.2. 2). Geneva, Switzerland.

18. Damor RD, Pithadia PR, Lodhiya KK, Mehta JP \& Yadav SB (2013). A study on assessment of nutritional and immunization status of under-five children in urban slums of Jamnagar city, Gujarat. Healthline 4: 35-39.

19. Chakraborty A, Dasgupta U, Mondal K, Das I, Sengupta D \& Mundle M (2014). Poor maternal education and incomplete immunization status are key predictors in development of under nutrition'-a descriptive study among under five children attending a tertiary care hospital in kolkata, west bengal. Indian J Prev Soc Med 45(1-2): 43.

20. Reno R \& Hyder A (2018). The Evidence Base for Social Determinants of Health as Risk Factors for Infant 
Mortality: A Systematic Scoping Review. $J$ of Health Care for the Poor and Underserved, 29(4): 1188-1208.

21. Peiris TDR \& Wijesinghe DGNG (2010). Nutritional status of under 5 year-old children and its relationship with maternal nutrition knowledge in Weeraketiya DS division of Sri Lanka.

22. Hirani SAA (2012). Malnutrition in young Pakistani children. $J$ of Ayub Med Coll 24(2): 150.

23. Mohseni M, Aryankhesal A \& Kalantari N (2018). Prevalence of Malnutrition Among Iran's Under Five-Year-Old Children and the Related Factors: A Systematic Review and MetaAnalysis. Iranian J of Pediat 28(1).
24. Mohseni M, Aryankhesal A \& Kalantari N (2018). Prevalence of Malnutrition Among Iran's Under Five-Year-Old Children and the Related Factors: A Systematic Review and MetaAnalysis. Iranian J of Pediat 28(1).

25. Miller JE \& Rodgers YV (2009). Mother's Education and Children's Nutritional Status: New Evidence from Cambodia. Asian Devel Rev 26(1): 131165.

26. Shafqat N, Manzoor S \& Abbasi S (2013). Relationship of Sociodemographic Factors with Malnutrition in Preschool Children: A Community Based Study. Pak J of Med Res 52(4). 